\title{
Refining Geomorphic Heterogeneity as a Framework for Assessing River Corridor Processes and Characteristics
}

\author{
Daniel Scott ${ }^{1}$, Scott Shahverdian ${ }^{2}$, Rebecca Flitcroft ${ }^{3}$, and Ellen Wohl ${ }^{4}$ \\ ${ }^{1}$ University of Washington Department of Earth and Space Sciences \\ ${ }^{2}$ Utah State University \\ ${ }^{3}$ USDA Forest Service Pacific Northwest Research Station \\ ${ }^{4}$ Colorado State University Department of Geosciences
}

June 15, 2022

\begin{abstract}
Spatial and temporal heterogeneity, or messiness, is a broadly desirable characteristic of river corridors and an indicator of many of the geomorphic processes that sustain fluvial ecosystems. However, quantifying geomorphic heterogeneity is complicated by a lack of consistent metrics, classification schemas for dividing the river corridor into the patches that form the basis for those metrics, and guidance on interpreting metrics. Drawing from both geomorphic and landscape ecology concepts, we offer ideas and guidance intended to help investigators, from researchers to restoration practitioners, more effectively and reliably use heterogeneity to describe river corridor processes and characteristics. We define geomorphic heterogeneity both spatially and temporally. Spatially, heterogeneity can be described by diversity, or the evenness and richness of geomorphic units, and spatial configuration, or the arrangement and shape of geomorphic units. Temporally, heterogeneity can be described by turnover rate, or the rate of change of geomorphic units. Interpretation of heterogeneity metrics depends integrally on the definition of the geomorphic unit schema on which metrics are based. Contextual information, such as measurements of process space (i.e., how much room a river has to move), disturbance frequency, and geomorphic trajectory, can also be key to interpreting measurements of heterogeneity. Geomorphic applications of heterogeneity require carefully defined geomorphic unit schemas that reflect processes and characteristics of interest, robust metrics of heterogeneity whose meaning is appropriate to the question at hand, and interpretation of those metrics based on the context of expected geomorphic processes and the disturbance regime.
\end{abstract}

Daniel N. Scott, Scott Shahverdian, Rebecca Flitcroft, Ellen Wohl

\begin{abstract}
Spatial and temporal heterogeneity, or messiness, is a broadly desirable characteristic of river corridors and an indicator of many of the geomorphic processes that sustain fluvial ecosystems. However, quantifying geomorphic heterogeneity is complicated by a lack of consistent metrics, classification schemas for dividing the river corridor into the patches that form the basis for those metrics, and guidance on interpreting metrics. Drawing from both geomorphic and landscape ecology concepts, we offer ideas and guidance intended to help investigators, from researchers to restoration practitioners, more effectively and reliably use heterogeneity to describe river corridor processes and characteristics. We define geomorphic heterogeneity both spatially and temporally. Spatially, heterogeneity can be described by diversity, or the evenness and richness of geomorphic units, and spatial configuration, or the arrangement and shape of geomorphic units. Temporally, heterogeneity can be described by turnover rate, or the rate of change of geomorphic units. Interpretation of heterogeneity metrics depends integrally on the definition of the geomorphic unit schema on which metrics
\end{abstract}


are based. Contextual information, such as measurements of process space (i.e., how much room a river has to move), disturbance frequency, and geomorphic trajectory, can also be key to interpreting measurements of heterogeneity. Geomorphic applications of heterogeneity require carefully defined geomorphic unit schemas that reflect processes and characteristics of interest, robust metrics of heterogeneity whose meaning is appropriate to the question at hand, and interpretation of those metrics based on the context of expected geomorphic processes and the disturbance regime.

\section{Motivation: Making Geomorphic Heterogeneity Assessments Mean- ingful}

Sustainable river corridor restoration and management integrally depend on the assessment and monitoring of geomorphic processes (Hiers et al., 2016; Palmer et al., 2005). Geomorphic heterogeneity provides a framework to facilitate such assessment. Geomorphic heterogeneity is the spatial and temporal variability of geomorphic units. Geomorphic units are patches of the landscape classified by morphology, substrate, vegetation type, and/or other characteristics relevant to the ecogeomorphic processes that reshape the landscape, namely the fluxes of water, sediment, and wood, all mediated by biological activity. Heterogeneity is both the foundation of and response to many of the physical, chemical, and ecological functions river corridors require and provide (Wohl, 2016).

Interconnected patches defined by geomorphic units can reflect physical, chemical, and biological characteristics across multiple scales depending on analysis objectives. The abundance of data and computational tools for assessing geomorphic heterogeneity make it deceptively easy to link heterogeneity metrics to ecosystem complexity and resilience. Spatial heterogeneity, commonly measured as the diversity of geomorphic units (e.g., Williams et al., 2020; Wohl \& Iskin, 2019; Wyrick \& Pasternack, 2014), is often measured for its own sake, with the argument that higher diversity in geomorphic units will increase the physical capacity to support biodiversity. Although overall heterogeneity of channels and river corridors can indicate their capacity to support local biodiversity (Amoros \& Bornette, 2002), more can be gained from targeted applications of various geomorphic heterogeneity metrics to describe specific processes of interest. Whereas geomorphic applications of heterogeneity have thus far focused primarily on diversity, heterogeneity metrics derived by landscape ecologists can also describe geomorphic unit spatial configuration, and when geomorphic units are mapped through time, their turnover can indicate temporal heterogeneity. This paper discusses how geomorphic practice can benefit from lessons learned from both landscape ecology and the authors' experience applying these methods.

Generally, it is most feasible to measure river corridor form to infer geomorphic processes because direct measurement of those processes (e.g., sediment flux sampling, repeat channel topographic measurements) tends to be costly. For instance, the abundance of habitat-providing geomorphic units can indicate whether a restoration project has created targeted habitat but does not adequately reflect the processes that could sustain such habitat. A measurement of geomorphic forms that would indicate whether geomorphic processes will sustain habitat would need to directly indicate the magnitude of those processes. Geomorphic processes, or the movement of water, sediment, and wood in conjunction with the actions of biota, create and maintain river corridor heterogeneity (Castro \& Thorne, 2019; Collins et al., 2012; Gurnell et al., 2005; Williams et al., 2020; Wohl \& Iskin, 2019; Yarnell et al., 2006). As such, geomorphic heterogeneity provides a framework for inferring causal links between form-based geomorphic metrics and geomorphic processes for a given river style (e.g., Constantine et al., 2014; Kasprak et al., 2017).

This conceptual discussion paper presents guidelines and ideas for how to quantify and interpret riverine geomorphic heterogeneity. Heterogeneity has long been recognized as a useful framework for understanding and describing river corridor ecology, (Cooper et al., 1997; Erös \& Lowe, 2019; Gustafson, 1998; Poole, 2002; Ward et al., 2002), but has not been developed as thoroughly for use in geomorphic applications. As such, this paper aims to: 1) provide guidance to those interested in using geomorphic heterogeneity as a 
tool to quantify geomorphic processes and forms and 2) spur further thought and inquiry into the use of heterogeneity as a framework for geomorphic investigations.

We focus primarily on patch-based heterogeneity metrics, or those parameterized by the abundance and spatial configuration of geomorphic unit classes that occupy discrete portions of the landscape, as opposed to those parameterized by continuous metrics (e.g., elevation; McGarigal et al., 2009; Scown et al., 2015). A patch-based framework can be directly applied to assemblages of geomorphic units that have direct relevance to geomorphic processes (Fryirs \& Brierley, 2021).

\section{Defining a Geomorphic Unit Schema}

As river corridors are reshaped by the erosion and deposition of sediment and large wood and the dynamics of biological communities (Castro \& Thorne, 2019), they develop a mosaic of patches defined by their landform classification (e.g., pool, bar), substrate (e.g., gravel, bedrock, soil, wood), and/or vegetation characteristics (e.g., canopy height, moisture tolerance, species assemblage, etc.), which we define as geomorphic units. A geomorphic unit schema is a collection of geomorphic units and their definitions specific to a given riverscape and analysis objectives. Geomorphic units can vary in size and definition depending on the forms and processes of interest, for instance, from a patch of fine sediment covering a square meter to an oxbow lake covering a square kilometer. The spatial scale of the geomorphic unit schema should be appropriate for the processes or characteristics of interest and will set the spatial scale over which heterogeneity can feasibly be assessed. When defined by both physical and biological characteristics, geomorphic (or, ecogeomorphic) units can reflect the interplay of geomorphic (e.g., erosion and deposition of sediment) and biotic processes (e.g., vegetation succession, salmon redd building) that define the ecogeomorphology of a river corridor (Johnson et al., 2019).

The definition of geomorphic units, or the geomorphic unit schema, is key to creating targeted geomorphic heterogeneity metrics. A river corridor can be classified by multiple geomorphic unit schemas, depending on the processes that shape the system (Brierley et al., 2010; Brierley \& Fryirs, 2000), questions of interest, and the feasibility of measurements. Geomorphic unit schemas have been developed to help standardize definitions of geomorphic unit classes (Belletti et al., 2017; Wheaton et al., 2015; Wyrick et al., 2014), but for the purposes of geomorphic heterogeneity, it is necessary only to develop a geomorphic unit schema that will represent the relevant geomorphic processes at a site (similar to selecting appropriate geoindicators for monitoring; Brierley et al., 2010).

The multi-channel, forested North Fork Teanaway River provides an example of how the same heterogeneity metric can be used with two different geomorphic unit schemas in the same location to address different objectives (Figure 1). A schema focused on the bankfull channel designed to indicate hydraulic heterogeneity (e.g., to reflect hydraulic complexity beneficial to fishes; Matheson et al., 2017; Naman et al., 2020) might consist of chutes, pools, glides, bars, runs, and riffles. High diversity (e.g., Simpson's diversity index, a measure of how many different units are present and how evenly distributed they are) of these units would likely reflect high hydraulic heterogeneity. Another channel-focused schema designed to indicate the capacity for wood storage might consist more simply of deep channel (pools and chutes lumped together), shallow channel (glides, bars, runs, and riffles all lumped together), and vegetated bars. High diversity of this simpler, three-unit schema would indicate a more even mix of landforms that tend to trap wood and those that tend to transport wood, and thus a higher wood storage capacity (i.e., enough space to get wood to trapping sites balanced with sufficient trapping sites to store that wood; Okitsu et al., 2021; Scott \& Wohl, 2018). Both schemas produce diversity values for the channel, and although these values are similar (both close to $88 \%$ of maximum diversity), they indicate completely different processes and are not meaningfully comparable. 


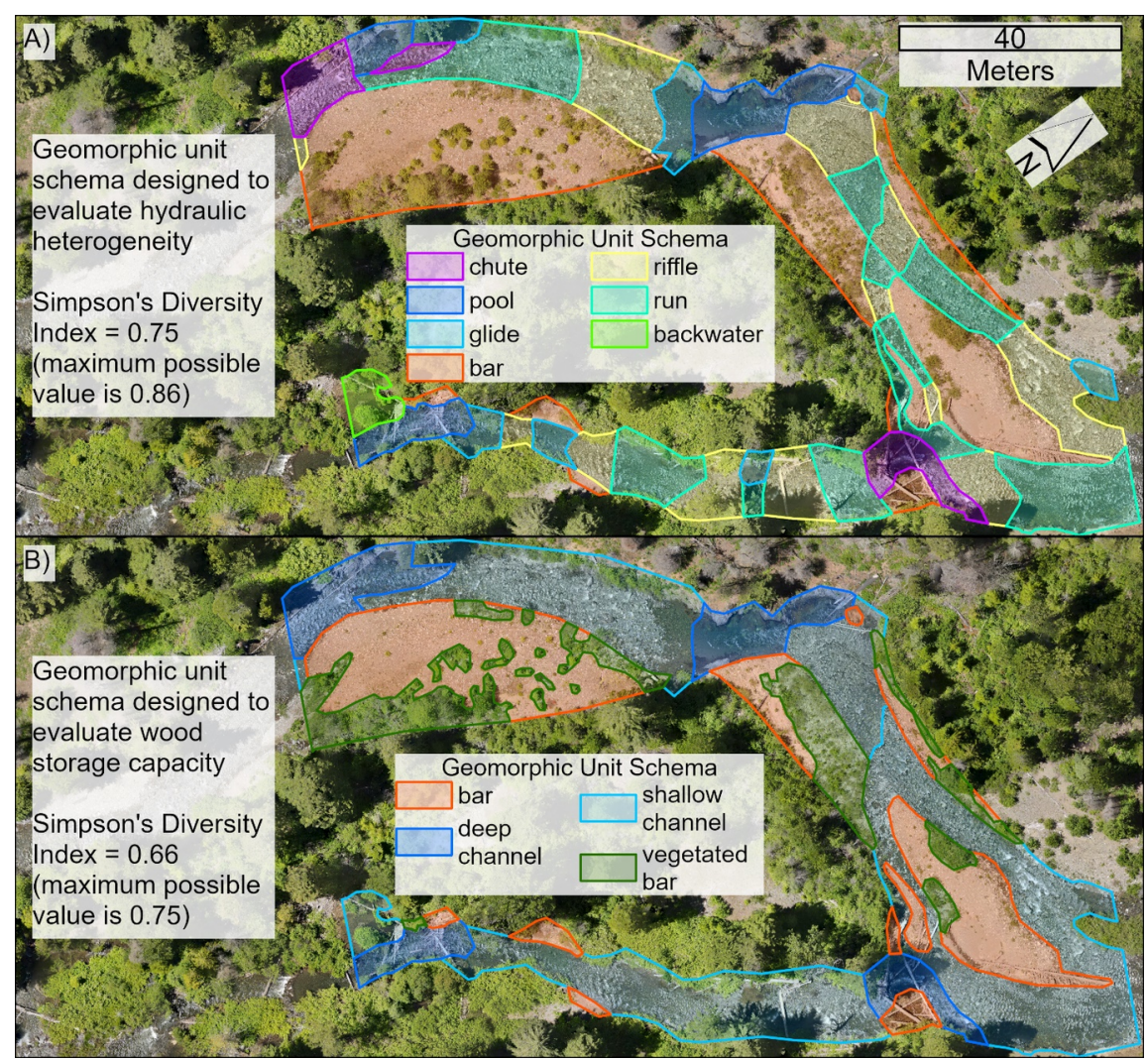

Figure 1: The North Fork Teanaway River, WA, USA shows how different geomorphic unit schemas produce different degrees of heterogeneity, even over the same area and using the same metric. Diversity indices computed for the same area will produce different values based on a hydraulic heterogeneity-focused schema (A) versus a wood storage capacity-focused schema (B), and those values are not meaningfully comparable.

\section{Spatial Geomorphic Heterogeneity}

The design of metrics to describe riverine forms and processes is limited only by the imagination, and this is especially true in the case of heterogeneity metrics, particularly when considering the array of geomorphic unit schemas that could be used to parameterize such metrics. Heterogeneity metrics have unique descriptive power in certain cases. An example is the ability of a river corridor to trap wood. Investigations of wood load variability and wood deposition patterns indicate that river corridors with a mix of landforms that transport wood and those that trap wood tend to accumulate the highest wood loads (Okitsu et al., 2021; Ruiz-Villanueva et al., 2016; Scott \& Wohl, 2018). How would one measure the degree to which geomorphic units are mixed together, as well as their spatial arrangement? Traditional metrics like channel width, slope, or even surface roughness are insufficient, but heterogeneity metrics provide descriptors aptly suited to this task, specifically the evenness and subdivision of landform patches.

Here, we discuss a few classes of metrics that we have found useful in investigating geomorphic processes. We refer readers to summaries of landscape pattern metrics from ecology for more detailed information (Magurran, 2021; McGarigal, 2012). 


\section{Measuring Geomorphic Unit Diversity}

Diversity measures both richness (total number of classes) and evenness (relative abundance of classes). If richness varies between sites of interest, diversity can be normalized by maximum diversity to describe evenness alone. Diversity is commonly measured using either the Shannon or Simpson diversity index. Shannon's diversity index is more sensitive to rare classes and more heavily weights richness, whereas Simpson's diversity index is less sensitive to rare classes, more heavily weights evenness, and can be readily interpreted as the probability of two randomly placed points landing in different geomorphic units (Nagendra, 2002; Somerfield et al., 2008).

Diversity metrics are useful when the evenness or number of geomorphic unit classes reflects processes of interest. For example, a high evenness of canopy heights (i.e., even area covered by low, medium, and high canopy) on young floodplains might indicate the prevalence of ongoing vegetation succession. Comparing canopy height evenness over time to flow or sediment flux could indicate whether either of those factors are limiting vegetation succession (e.g., a lack of cottonwood recruitment due to flow regulation; Braatne et al., 2007)). Alternatively, the richness of in-channel geomorphic units (e.g., pools and bars of varying origin, further subdivided by surface grain size) could indicate the effectiveness of in-channel structures like wood and patches of vegetation at producing more variable sediment erosion and deposition patterns, assuming that greater hydraulic variability caused by wood and vegetation would result in a greater variety of geomorphic units (Fryirs \& Brierley, 2021). Finally, the diversity (i.e., both richness and evenness) of floodplain geomorphic units (e.g., scroll bars, oxbow lakes, relict channels, all further classified by vegetation community) could reflect the variability and relative dominance of processes like avulsion and channel migration in reshaping the river corridor (Slingerland \& Smith, 2004).

\section{Measuring the Spatial Configuration of Geomorphic Units}

Diversity (i.e., richness and evenness) does not account for the spatial configuration, or arrangement, of geomorphic units. As such, diversity may not indicate overall complexity. This means that in some cases, diversity metrics will need to be supplemented with spatial configuration metrics (Figure 2).

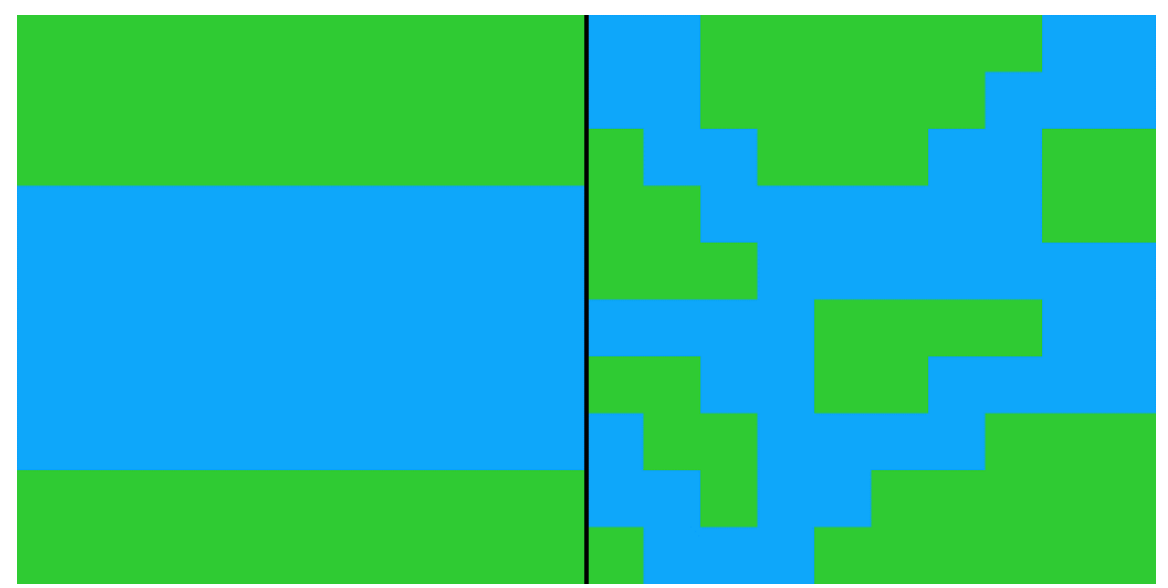

Figure 2: Two hypothetical landscapes with identical evenness (50 blue squares, 50 green squares), but very different spatial configuration.

There are many ways to describe spatial configuration, ranging from metrics of patch type interspersion to metrics of patch shape or contrast between patches (McGarigal, 2012). Many spatial configuration metrics correlate (Frazier \& Kedron, 2017), meaning that an investigator must choose between multiple potentially suitable metrics for a given application(for more details, see literature from landscape ecology, 
e.g., Gustafson, 2019; McGarigal, 2012). The aspects of spatial configuration that tend to be geomorphically relevant include subdivision, or the degree to which the riverscape is broken up (e.g., by multiple channels or patches of vegetation; Figure 3A, B), geomorphic unit edge density (e.g., bank complexity; Figure 3C, D), and aggregation or dispersion, or the degree to which specific geomorphic units are clumped together versus spread out across the river corridor (e.g., wood stored as individual pieces versus large jams; Figure 3E, F). Figure 3 demonstrates high versus low values of each of these types of spatial configuration with multiple metrics for each. Many metrics are redundant, as Figure 3 demonstrates, so it is important to choose one that is well-suited for site conditions, the question of interest, and available data.

Spatial configuration can be measured at the patch (e.g., the shape of a single patch, like a pool), class (e.g., the isolation of a particular geomorphic unit type, like all pools), or landscape level (e.g., the subdivision of multiple geomorphic unit types, like all in-channel units) (McGarigal, 2012). However, most geomorphic applications will likely focus on the class or landscape level.

Class level spatial configuration metrics are useful when individual geomorphic unit classes indicate important characteristics. For instance, the patch density of vegetated islands (i.e., the number of islands per unit area) is a suitable measurement of channel node or bifurcation density. The edge density (i.e., edge length per unit area or unit centerline length) of channels can indicate bank planform roughness (Figure 3C, D). The aggregation (or isolation) of wood can indicate patterns of wood transport and deposition, such as jam formation versus deposition of dispersed pieces (Figure 3E, F).

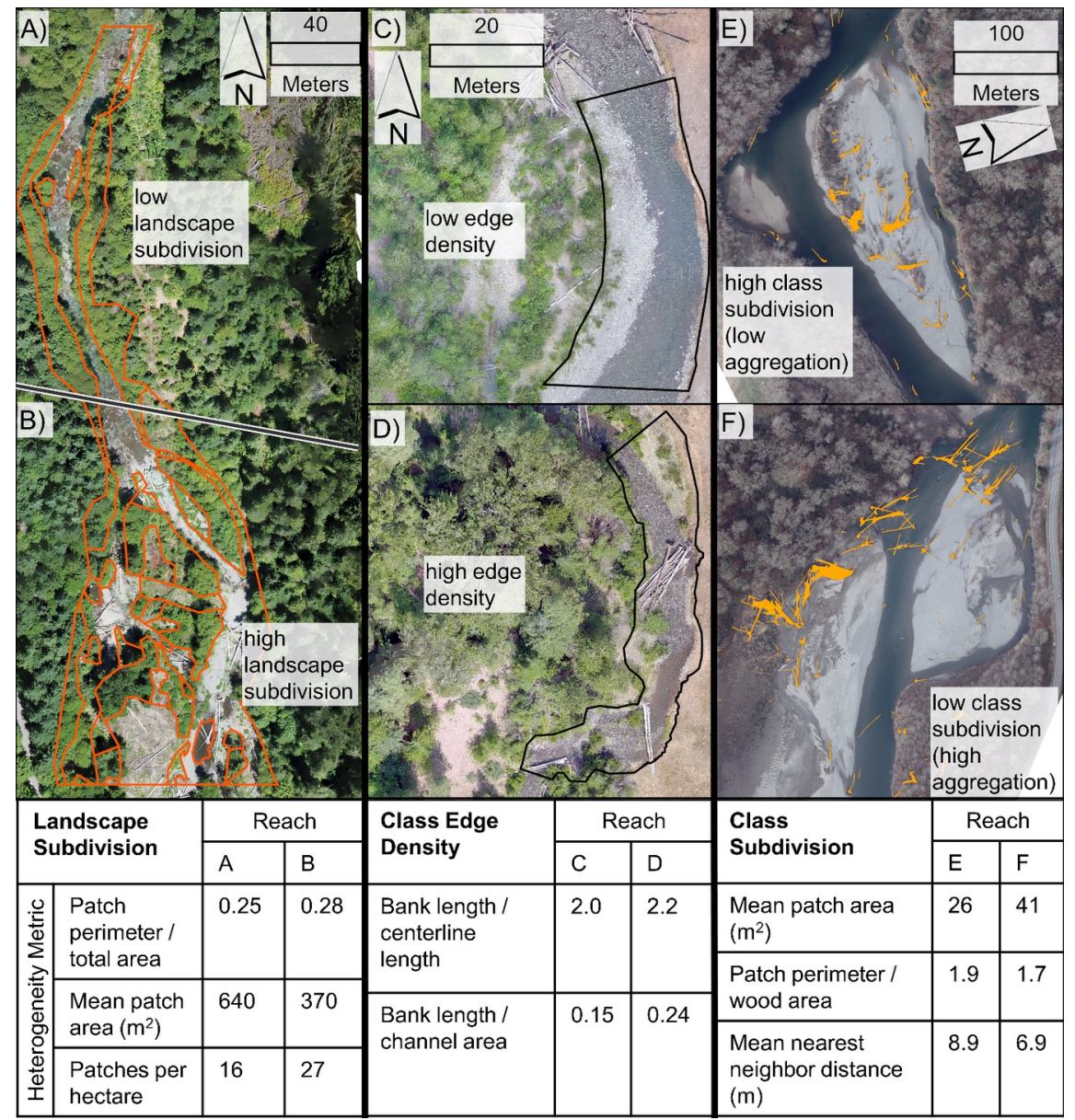

Figure 3: Examples of varying landscape subdivision (A and B; Deer Creek, OR), channel edge density (B 
and C; North Fork Teanaway River, WA), and class level subdivision of wood (D and E; Snoqualmie River, WA). Multiple metrics show differences in spatial configuration between contrasting reaches, all with slightly differing utility and interpretation.

Landscape level spatial configuration metrics (i.e., those computed across multiple geomorphic unit classes) can be a proxy for characteristics that can be difficult to directly measure. For instance, if lacking quantitative bathymetric data, one could use aerial imagery to map the channel using a geomorphic unit schema defined by units with varying relative elevations (e.g., pools, chutes, riffles, and bars, in order of increasing relative elevation). The subdivision or edge density of those units could indicate variability in channel bed elevation and resulting hydraulic roughness.

\section{Temporal Geomorphic Heterogeneity}

Geomorphic heterogeneity includes both spatial and temporal components. While spatial heterogeneity describes variability in geomorphic units from one place to another, temporal heterogeneity describes variability in geomorphic units through time in a single place. Temporal heterogeneity is simply the rate at which geomorphic units change, or turnover, from one unit to another.

Some degree of disturbance and turnover of geomorphic units is usually a prerequisite for sustained spatial heterogeneity, as disturbances rearrange geomorphic units (Rice et al., 2012; Townsend, 1989) and the riverine habitat mosaic (Arscott et al., 2002; Stanford et al., 2005; Ward et al., 2002; Willig \& Presley, 2018). Rivers that lack either driving forces (e.g., geomorphically effective flows) or forms (e.g., wood that increases roughness) that generate disturbance and turnover of geomorphic units tend towards a more homogenous state (flow regulation is a good example; Gendaszek et al., 2012; Graf, 2006). However, constant, highmagnitude disturbance is not necessary to sustain a heterogeneous character - different river systems (e.g., monsoon-dominated versus snowmelt-dominated) and different portions within a river system (e.g., channel versus floodplain) will require different turnover rates, or different disturbance regimes, to sustain different aspects of spatial heterogeneity.

Although one-time alterations, perhaps due to river restoration (e.g., Stoffers et al., 2020) or unusually highmagnitude flows (e.g., Gendaszek et al., 2012), can generate high spatial heterogeneity, estimating turnover rate can help determine whether those short-term gains are likely to be sustained, or whether an alternative state has been reached (Livers et al., 2018; Phillips \& Van Dyke, 2016). For example, comparing postrestoration to pre-restoration turnover rate could indicate restoration effects on the overall erodibility of the valley bottom. Turnover rate might indicate whether that restoration simply made the landscape more heterogeneous or has reactivated the processes needed to sustain that heterogeneity.

\section{Measuring Temporal Dynamism}

Temporal heterogeneity can be expressed as a turnover rate (change per unit time) or its reciprocal, turnover time (time required for the entire landscape or portion of the landscape to change), both typically derived from many observations of change. Temporal heterogeneity can be calculated at the level of individual landforms, analogous to class level spatial heterogeneity metrics (e.g., floodplain turnover; Beechie et al., 2006; O'Connor et al., 2003) or for entire areas, analogous to landscape level spatial heterogeneity metrics (e.g., the turnover rate of all in-channel landforms). It is important to note that different portions of the river corridor may be expected to change at different rates, so measuring temporal heterogeneity over the entire river corridor may be misleading, whereas measuring it separately, for instance, for active channels versus floodplain surfaces versus terraces, may better represent the real propensity of the landscape to change.

Regardless of spatial scale, the interpretation of temporal heterogeneity metrics depend strongly on the definition of geomorphic units. In a meandering river, for instance, a geomorphic unit schema defined only by channel and floodplain units will have a longer average turnover time than one defined by low flow wetted 
channel, bars, early successional floodplain, and late successional floodplain, as the more detailed geomorphic unit schema will be more sensitive to frequent changes, such as vegetation succession.

Two pieces of contextual information are required to unbiasedly assess temporal heterogeneity: observation frequency and disturbance frequency. Observation frequency dictates the maximum detectable turnover rate, as geomorphic units cannot be observed to change more times than there are observations. Observations should be timed appropriately to the frequency with which geomorphic units are expected to change. For example, observations every 5 years will only provide a minimum estimate - likely a dramatic underestimate - of the turnover rate of fast-changing geomorphic units, like grain size patches in a gravel-bed river. Disturbance frequency, or the frequency of events that can change geomorphic units, sets the expectation for maximum potential temporal heterogeneity. A system with very low in-channel geomorphic unit turnover rate might be behaving just as expected if there have been no geomorphically effective flows in the period of measurement, but that same turnover rate over a period of multiple major floods would likely indicate a channel boundary that is very resistant to change, assuming observations were timed appropriately. Dating of floodplain strata or the use of historical imagery can be effective ways of extending the period over which temporal heterogeneity is measured, which can be key to measuring turnover rates for slow-changing geomorphic units. It stands to reason that normalizing turnover rate by dividing it by disturbance frequency can be a useful way of comparing across sites with similar geomorphic processes but differing rates of those processes (e.g., different flow regimes).

\section{Contextualizing Geomorphic Heterogeneity}

Geomorphic heterogeneity metrics pair well with descriptors of process space, utilization of process space, and geomorphic trajectory. Confinement, or process space (sensu Ciotti et al., 2021) describes the proportion of the valley bottom over which fluvial processes are active (e.g., the proportion of the valley bottom occupied by channels and floodplains). Process space utilization is the degree to which the river is actively reshaping the space available to it (e.g., the proportion of the channel and floodplain area occupied by channels either at a given time or cumulatively over a period of time). Rivers with greater process space can exhibit higher lateral connectivity, lower longitudinal connectivity, and higher spatial heterogeneity (Choné \& Biron, 2016; Fotherby, 2009; Williams et al., 2020; Wohl et al., 2018; Wohl \& Iskin, 2019). Because process space can regulate spatial heterogeneity, it can help to measure process space to aid in interpreting either spatial or temporal variability in heterogeneity metrics.

Although measurements of process space can identify constraints on the river corridor, measurements of process space utilization, or the degree to which the river is actively reshaping its fluvial process space, can identify deficiencies in the ingredients necessary to reshape the available space (e.g., flow, wood, sediment, etc.). Process space utilization can be measured by the proportion of the channel and floodplain area occupied by channels either at a given time or cumulatively over a period of time. Temporally, process space utilization can be measured as the turnover rate of the fluvial process space. Process space utilization can indicate the effects of different magnitudes of forcings (e.g., various flood magnitudes or durations), provide key context for observed temporal heterogeneity, or highlight hotspots of change that have caused changes in landscape scale spatial heterogeneity.

Finally, geomorphic trajectory (Fryirs et al., 2012; Mould \& Fryirs, 2018; Surian et al., 2009), especially the trajectory of spatial heterogeneity metrics, can indicate whether the geomorphic processes that sustain heterogeneity are indeed active. If geomorphic heterogeneity is being sustained or increasing through time and the metrics used to infer geomorphic heterogeneity adequately reflect active geomorphic processes, then it stands to reason that geomorphic processes are active or even increasing in magnitude or rate. 


\section{Summary Recommendations for Applying Geomorphic Heterogenei- ty}

Here, we have discussed how metrics of spatial and temporal heterogeneity can represent geomorphic processes and characteristics. Table 1 summarizes the aspects of heterogeneity discussed above and their meaning.

Table 1: Aspects of heterogeneity and their meaning in a geomorphic context.

\begin{tabular}{llll}
\hline Heterogeneity Aspect & Heterogeneity Aspect & Typical Application Level & Meaning \\
\hline Spatial Heterogeneity & Diversity (richness and/or evenness) & Landscape & Richness describes how \\
& Spatial Configuration & Class or Landscape & Describes the geometry \\
Temporal Heterogeneity & Temporal Heterogeneity & Class or Landscape & Describes the rate at wh \\
\hline
\end{tabular}

In conclusion, we suggest eight considerations when evaluating geomorphic heterogeneity in river corridors:

There is no single degree of geomorphic heterogeneity that defines a well-functioning river corridor. Geomorphic heterogeneity expectations (or, for restoration, goals) will differ depending on active geomorphic processes, process space, disturbance regime, the metrics and geomorphic unit schema being applied, and what people value about a river corridor.

Carefully design geomorphic unit schemas to address specific objectives. To evaluate a specific process, consider what components of the river corridor that process tends to alter, and how to define those components in a way that is relevant for that process.

Select heterogeneity metrics that will describe the characteristics of geomorphic unit assemblages that relate to specific objectives. Different metrics are sensitive to different characteristic, such as spatial configuration, evenness, or turnover. Choose metrics that conceptually represent characteristics of interest, then check that they match qualitative observations across a range of possible conditions.

Interpret spatial heterogeneity metrics in the context of potential heterogeneity, fluvial process space, and the processes that drive geomorphic change. Measurements of spatial heterogeneity should usually be contextualized by expectations about the maximum level of heterogeneity a river corridor might be expected to achieve, based on available fluvial process space, flows of water, wood, and sediment, and ecological function.

Use multiple metrics to achieve more holistic descriptions of heterogeneity. For instance, evenness and subdivision metrics can together describe overall valley bottom heterogeneity better than either metric alone.

Set expectations for heterogeneity that are specific to the system in question. Applying the same geomorphic unit schema across rivers with very different characteristics and active processes may yield misleading comparisons unless the schemas and metrics applied are comparable. It may be more appropriate to compare heterogeneity metrics based on unique geomorphic unit schemas specific to each river system, but that reflect analogous processes.

Frame expectations of heterogeneity based on scale. Landform spacing is scale-dependent (e.g., poolriffle spacing depends on channel width; Gregory et al., 1994), meaning that so too are heterogeneity metrics that describe them (e.g., compare the narrow versus wide channels in Figure 1). Similarly, measurements of turnover rate depend on the observation interval relative to disturbance frequency. Varying spatial or temporal scales will produce different and potentially incomparable heterogeneity metrics.

Provide context for spatial heterogeneity using temporal heterogeneity. Although spatial heterogeneity alone can be useful, it may produce misleading conclusions without the context that comes from 
evaluating turnover rate. This is especially important when the sustainability of a heterogeneous state is in question.

Geomorphic heterogeneity, or the spatial and temporal variability in geomorphic units, is a useful tool that allows investigators to infer geomorphic processes and quantify characteristics hypothesized to regulate those processes. By applying the concepts discussed here, we hope that investigators can continue to develop novel and effective applications of geomorphic heterogeneity to improve our ability to describe river forms and processes.

\section{Acknowledgements and Data Availability}

Funding for the development of methods discussed here was provided by the United States Forest Service National Stream Aquatic Ecology Center and Pacific Northwest Research Station, as well as the McKenzie Watershed Council. Thanks to Brian Collins, Todd Hurley, Kate Meyer, Jared Weybright, Johan Hogervorst, Matt Helstab, and Ryan DeKnikker for discussions that helped refine the ideas presented here. Thanks to two anonymous reviewers for comments that helped improve the manuscript.

Data shown in this manuscript is solely to provide illustrative examples of various heterogeneity metrics, not as accurate representations of the landscapes shown.

\section{References}

Amoros, C., \& Bornette, G. (2002). Connectivity and biocomplexity in waterbodies of riverine floodplains: Connectivity and biocomplexity in riverine floodplains. Freshwater Biology, 47(4), 761-776. https://doi.org/10.1046/j.1365-2427.2002.00905.x

Arscott, D. B., Tockner, K., van der Nat, D., \& Ward, J. V. (2002). Aquatic Habitat Dynamics along a Braided Alpine River Ecosystem (Tagliamento River, Northeast Italy). Ecosystems, 5(8), $0802-0814$. https://doi.org/10.1007/s10021-002-0192-7

Beechie, T. J., Liermann, M., Pollock, M. M., Baker, S., \& Davies, J. (2006). Channel pattern and river-floodplain dynamics in forested mountain river systems. Geomorphology, 78(1-2), 124-141. https://doi.org/10.1016/j.geomorph.2006.01.030

Belletti, B., Rinaldi, M., Bussettini, M., Comiti, F., Gurnell, A. M., Mao, L., Nardi, L., \& Vezza, P. (2017). Characterising physical habitats and fluvial hydromorphology: A new system for the survey and classification of river geomorphic units. Geomorphology, 283, 143-157. https://doi.org/10.1016/j.geomorph.2017.01.032

Braatne, J. H., Jamieson, R., Gill, K. M., \& Rood, S. B. (2007). Instream flows and the decline of riparian cottonwoods along the Yakima River, Washington, USA. River Research and Applications, 23(3), $247-267$. https://doi.org/10.1002/rra.978

Brierley, G., \& Fryirs, K. A. (2000). River Styles, a Geomorphic Approach to Catchment Characterization: Implications for River Rehabilitation in Bega Catchment, New South Wales, Australia. Environmental Management, 25(6), 661-679. https://doi.org/10.1007/s002670010052

Brierley, G., Reid, H., Fryirs, K., \& Trahan, N. (2010). What are we monitoring and why? Using geomorphic principles to frame eco-hydrological assessments of river condition. Science of the Total Environment, 408, 9 .

Castro, J. M., \& Thorne, C. R. (2019). The stream evolution triangle: Integrating geology, hydrology, and biology. River Research and Applications, 35(4), 315-326. https://doi.org/10.1002/rra.3421 
Choné, G., \& Biron, P. M. (2016). Assessing the Relationship Between River Mobility and Habitat. River Research and Applications, 32(4), 528-539. https://doi.org/10.1002/rra.2896

Ciotti, D. C., Mckee, J., Pope, K. L., Kondolf, G. M., \& Pollock, M. M. (2021). Design Criteria for ProcessBased Restoration of Fluvial Systems. BioScience, 71 (8), 831-845. https://doi.org/10.1093/biosci/biab065

Collins, B. D., Montgomery, D. R., Fetherston, K. L., \& Abbe, T. B. (2012). The floodplain largewood cycle hypothesis: A mechanism for the physical and biotic structuring of temperate forested alluvial valleys in the North Pacific coastal ecoregion. Geomorphology, 139-140, 460-470. https://doi.org/10.1016/j.geomorph.2011.11.011

Constantine, J. A., Dunne, T., Ahmed, J., Legleiter, C., \& Lazarus, E. D. (2014). Sediment supply as a driver of river meandering and floodplain evolution in the Amazon Basin. Nature Geoscience, 7(12), 899903. https://doi.org/10.1038/ngeo2282

Cooper, S. D., Barmuta, L., Sarnelle, O., Kratz, K., \& Diehl, S. (1997). Quantifying Spatial Heterogeneity in Streams. Journal of the North American Benthological Society, 16(1), 174-188. https://doi.org/10.2307/1468250

Erôs, T., \& Lowe, W. H. (2019). The Landscape Ecology of Rivers: From Patch-Based to Spatial Network Analyses. Current Landscape Ecology Reports, 4, 103-112. https://doi.org/10.1007/s40823-019-00044-6

Fotherby, L. M. (2009). Valley confinement as a factor of braided river pattern for the Platte River. Geomorphology, 103(4), 562-576. https://doi.org/10.1016/j.geomorph.2008.08.001

Frazier, A. E., \& Kedron, P. (2017). Landscape Metrics: Past Progress and Future Directions. Current Landscape Ecology Reports, 2(3), 63-72. https://doi.org/10.1007/s40823-017-0026-0

Fryirs, K., \& Brierley, G. (2021). Assemblages of geomorphic units: A building block approach to analysis and interpretation of river character, behaviour, condition and recovery. Earth Surface Processes and Landforms, esp.5264. https://doi.org/10.1002/esp.5264

Fryirs, K., Brierley, G. J., \& Erskine, W. D. (2012). Use of ergodic reasoning to reconstruct the historical range of variability and evolutionary trajectory of rivers. Earth Surface Processes and Landforms, 37(7), 763-773. https://doi.org/10.1002/esp.3210

Gendaszek, A. S., Magirl, C. S., \& Czuba, C. R. (2012). Geomorphic response to flow regulation and channel and floodplain alteration in the gravel-bedded Cedar River, Washington, USA. Geomorphology, 179, 258-268. https://doi.org/10.1016/j.geomorph.2012.08.017

Graf, W. L. (2006). Downstream hydrologic and geomorphic effects of large dams on American rivers. Geomorphology, 79(3-4), 336-360. https://doi.org/10.1016/j.geomorph.2006.06.022

Gregory, K. J., Gurnell, A. M., Hill, C. T., \& Tooth, S. (1994). Stability of the pool-riffle sequence in changing river channels. Regulated Rivers: Research \& Management, 9(1), 35-43. https://doi.org/10.1002/rrr.3450090104

Gurnell, A., Tockner, K., Edwards, P., \& Petts, G. (2005). Effects of deposited wood on biocomplexity of river corridors. Frontiers in Ecology and the Environment, 3(7), 377-382. https://doi.org/10.1890/15409295(2005)003[0377:EODWOB]2.0.CO;2

Gustafson, E. J. (1998). Quantifying Landscape Spatial Pattern: What Is the State of the Art? Ecosystems, $1,143-156$.

Gustafson, E. J. (2019). How has the state-of-the-art for quantification of landscape pattern advanced in the twenty-first century? Landscape Ecology, 34 (9), 2065-2072. https://doi.org/10.1007/s10980-018-0709-x

Hiers, J. K., Jackson, S. T., Hobbs, R. J., Bernhardt, E. S., \& Valentine, L. E. (2016). The Precision Problem in Conservation and Restoration. Trends in Ecology 86 Evolution, 31(11), 820-830. 
https://doi.org/10.1016/j.tree.2016.08.001

Johnson, M. F., Thorne, C. R., Castro, J. M., Kondolf, G. M., Mazzacano, C. S., Rood, S. B., \& Westbrook, C. (2019). Biomic river restoration: A new focus for river management. River Research and Applications. https://doi.org/10.1002/rra.3529

Kasprak, A., Caster, J., Bangen, S. G., \& Sankey, J. B. (2017). Geomorphic process from topographic form: Automating the interpretation of repeat survey data in river valleys. Earth Surface Processes and Landforms, 42(12), 1872-1883. https://doi.org/10.1002/esp.4143

Livers, B., Wohl, E., Jackson, K. J., \& Sutfin, N. A. (2018). Historical land use as a driver of alternative states for stream form and function in forested mountain watersheds of the Southern Rocky Mountains. Earth Surface Processes and Landforms, 43(3), 669-684. https://doi.org/10.1002/esp.4275

Magurran, A. E. (2021). Measuring biological diversity. Current Biology, 31(19), R1174-R1177. https://doi.org/10.1016/j.cub.2021.07.049

Matheson, A., Thoms, M., \& Reid, M. (2017). Does reintroducing large wood influence the hydraulic landscape of a lowland river system? Geomorphology, 292, 128-141. https://doi.org/10.1016/j.geomorph.2017.03.035

McGarigal, K. (2012). Landscape Pattern Metrics. In A. H. El-Shaarawi \& W. W. Piegorsch (Eds.), Encyclopedia of Environmetrics (1st ed.). Wiley. https://doi.org/10.1002/9780470057339.val006.pub2

McGarigal, K., Tagil, S., \& Cushman, S. A. (2009). Surface metrics: An alternative to patch metrics for the quantification of landscape structure. Landscape Ecology, 24(3), 433-450. https://doi.org/10.1007/s10980009-9327-y

Mould, S., \& Fryirs, K. (2018). Contextualising the trajectory of geomorphic river recovery with environmental history to support river management. Applied Geography, 94, 130-146. https://doi.org/10.1016/j.apgeog.2018.03.008

Nagendra, H. (2002). Opposite trends in response for the Shannon and Simpson indices of landscape diversity. Applied Geography, 22(2), 175-186. https://doi.org/10.1016/S0143-6228(02)00002-4

Naman, S. M., Rosenfeld, J. S., Jordison, E., Kuzyk, M., \& Eaton, B. C. (2020). Exploitation of Velocity Gradients by Sympatric Stream Salmonids: Basic Insights and Implications for Instream Flow Management. North American Journal of Fisheries Management, 40(2), 320-329. https://doi.org/10.1002/nafm.10411

O'Connor, J. E., Jones, M. A., \& Haluska, T. L. (2003). Flood plain and channel dynamics of the Quinault and Queets Rivers, Washington, USA. Geomorphology, 51(1-3), 31-59. https://doi.org/10.1016/S0169$555 \mathrm{X}(02) 00324-0$

Okitsu, T., Iwasaki, T., Kyuka, T., \& Shimizu, Y. (2021). The Role of Large-Scale Bedforms in Driftwood Storage Mechanism in Rivers. Water, 13(6), 811. https://doi.org/10.3390/w13060811

Palmer, M. A., Bernhardt, E. S., Allan, J. D., Lake, P. S., Alexander, G., Brooks, S., Carr, J., Clayton, S., Dahm, C. N., Follstad Shah, J., Galat, D. L., Loss, S. G., Goodwin, P., Hart, D. D., Hassett, B., Jenkinson, R., Kondolf, G. M., Lave, R., Meyer, J. L., ... Sudduth, E. (2005). Standards for ecologically successful river restoration: Ecological success in river restoration. Journal of Applied Ecology, 42(2), 208217. https://doi.org/10.1111/j.1365-2664.2005.01004.x

Phillips, J. D., \& Van Dyke, C. (2016). Principles of geomorphic disturbance and recovery in response to storms. Earth Surface Processes and Landforms, 41(7), 971-979. https://doi.org/10.1002/esp.3912

Poole, G. C. (2002). Fluvial landscape ecology: Addressing uniqueness within the river discontinuum: Fluvial landscape ecology. Freshwater Biology, 47(4), 641-660. https://doi.org/10.1046/j.1365-2427.2002.00922.x 
Rice, S., Stoffel, M., Turowski, J. M., \& Wolf, A. (2012). Disturbance regimes at the interface of geomorphology and ecology. Earth Surface Processes and Landforms, 37(15), 1678-1682. https://doi.org/10.1002/esp.3326

Ruiz-Villanueva, V., Wyżga, B., Hajdukiewicz, H., \& Stoffel, M. (2016). Exploring large wood retention and deposition in contrasting river morphologies linking numerical modelling and field observations: Modelling Wood Retention and Deposition. Earth Surface Processes and Landforms, 41(4), 446-459. https://doi.org/10.1002/esp.3832

Scott, D. N., \& Wohl, E. E. (2018). Natural and Anthropogenic Controls on Wood Loads in River Corridors of the Rocky, Cascade, and Olympic Mountains, USA. Water Resources Research, 54 (10), 7893-7909. https://doi.org/10.1029/2018WR022754

Scown, M. W., Thoms, M. C., \& De Jager, N. R. (2015). Floodplain complexity and surface metrics: Influences of scale and geomorphology. Geomorphology, 245, 102-116. https://doi.org/10.1016/j.geomorph.2015.05.024

Slingerland, R., \& Smith, N. D. (2004). River Avulsions and Their Deposits. Annual Review of Earth and Planetary Sciences, 32(1), 257-285. https://doi.org/10.1146/annurev.earth.32.101802.120201

Somerfield, P. J., Clarke, K. R., \& Warwick, R. M. (2008). Simpson Index. In S. E. Jørgensen \& B. D. Fath (Eds.), Encyclopedia of Ecology (pp. 3252-3255). Academic Press. https://doi.org/10.1016/B978-0080454054.00133-6

Stanford, J. A., Lorang, M. S., \& Hauer, F. R. (2005). The shifting habitat mosaic of river ecosystems. SIL Proceedings, 1922-2010, 29(1), 123-136. https://doi.org/10.1080/03680770.2005.11901979

Stoffers, T., Collas, F. P. L., Buijse, A. D., Geerling, G. W., Jans, L. H., van Kessel, N., Verreth, J. A. J., \& Nagelkerke, L. A. J. (2020). 30 years of large river restoration: How long do restored floodplain channels remain suitable for targeted rheophilic fishes in the lower river Rhine? Science of The Total Environment, 142931. https://doi.org/10.1016/j.scitotenv.2020.142931

Surian, N., Ziliani, L., Comiti, F., Lenzi, M. A., \& Mao, L. (2009). Channel adjustments and alteration of sediment fluxes in gravel-bed rivers of North-Eastern Italy: Potentials and limitations for channel recovery. River Research and Applications, 25(5), 551-567. https://doi.org/10.1002/rra.1231

Townsend, C. R. (1989). The Patch Dynamics Concept of Stream Community Ecology. Journal of the North American Benthological Society, 8(1), 36-50. https://doi.org/10.2307/1467400

Ward, J. V., Tockner, K., Arscott, D. B., \& Claret, C. (2002). Riverine landscape diversity. Freshwater Biology, 47(4), 517-539. https://doi.org/10.1046/j.1365-2427.2002.00893.x

Wheaton, J. M., Fryirs, K. A., Brierley, G., Bangen, S. G., Bouwes, N., \& O'Brien, G. (2015). Geomorphic mapping and taxonomy of fluvial landforms. Geomorphology, 248, 273-295. https://doi.org/10.1016/j.geomorph.2015.07.010

Williams, R. D., Bangen, S., Gillies, E., Kramer, N., Moir, H., \& Wheaton, J. (2020). Let the river erode! Enabling lateral migration increases geomorphic unit diversity. Science of The Total Environment, 136817. https://doi.org/10.1016/j.scitotenv.2020.136817

Willig, M. R., \& Presley, S. J. (2018). Biodiversity and Disturbance. In Encyclopedia of the Anthropocene (pp. 45-51). Elsevier. https://doi.org/10.1016/B978-0-12-809665-9.09813-X

Wohl, E. (2016). Messy rivers are healthy rivers: The role of physical complexity in sustaining ecosystem processes. River Flow 2016, 24-27. https://doi.org/10.1201/9781315644479-8

Wohl, E., \& Iskin, E. (2019). Patterns of Floodplain Spatial Heterogeneity in the Southern Rockies, USA. Geophysical Research Letters, 2019GL083140. https://doi.org/10.1029/2019GL083140 
Wohl, E., Lininger, K. B., \& Scott, D. N. (2018). River beads as a conceptual framework for building carbon storage and resilience to extreme climate events into river management. Biogeochemistry, 141(3), 365-383. https://doi.org/10.1007/s10533-017-0397-7

Wyrick, J. R., \& Pasternack, G. B. (2014). Geospatial organization of fluvial landforms in a gravel-cobble river: Beyond the riffle-pool couplet. Geomorphology, 213, 48-65. https://doi.org/10.1016/j.geomorph.2013.12.040

Wyrick, J. R., Senter, A. E., \& Pasternack, G. B. (2014). Revealing the natural complexity of fluvial morphology through 2D hydrodynamic delineation of river landforms. Geomorphology, 210, 14-22. https://doi.org/10.1016/j.geomorph.2013.12.013

Yarnell, S. M., Mount, J. F., \& Larsen, E. W. (2006). The influence of relative sediment supply on riverine habitat heterogeneity. Geomorphology, 80(3-4), 310-324. https://doi.org/10.1016/j.geomorph.2006.03.005 